\title{
U.S. NRC EXPERIENCE WITH UNDERVOLTAGE TRIP ATTACHMENTS ON REACTOR TRIP SWITCHGEAR
}

Robert J. Wright

Vincent S. Noonan

United States Nuclear Regulatory Commission

Washington, D.C. 20555

Abstract - An overview of the failures of reactor trip switchgear to trip soley on loss of voltage is presented. There are three types of switchgear in reactor protection systems in pressurized water reactors in the United States. The review of the failures to date and the corrective actions taken suggest that proper maintenance and surveillance testing of existing undervoltage trip attachments on reactor trip switchgear should reduce substantially the number of failures.

\section{INTRODUCTION}

General Design Criteria 23 of 10 CFR 50 , Appendix A states, "The protection system shall be designed to fail into a safe state or into a state demonstrated to be acceptable on some other defined basis if conditions such as disconnection of the system, loss of energy (e.g., electric power, instrument air), or postulated adverse environments (e.g., extreme heat or cold, fire, pressure, steam, water and radiation) are experienced." The most notable failure of switchgear to trip via the loss of power occurred at the Salem Nuclear Power Plant on February 22 and 25,1983 . This incident is documented thoroughly in [1] and [2]. Since then there have been other incidences of failure to trip on loss of voltage. Every type of switchgear used for automatic tripping in the reactor protection systems in pressurized water reactor nuclear plants has experienced anomalies associated with the undervoltage trip function from failure to trip, to slow trip response times, to missing or broken parts on the undervoltage trip attachment. Fortunately only Salem involved an Anticipated Transient Without Scram (ATWS). Most of the anomalies occurred during scheduled surveillance or planned tests. As there is a redundancy of switchgear in the reactor protection system coupled with a diversity of paths to initiate a trip, there has been no threat to the public health and safety.

The three types of reactor trip switchgear in nuclear service in reactor protection systems in pressurized water reactors are the Westinghouse DB-50 (W-DB-50), the Westinghouse DS-416 (W-DS-416) and the General Electric AK-2 (GE-AK-2) type. The GE-AK-2 type switchgear is used in plants where the Nuclear Steam Supply System has been supplied by Combustion Engineering (CE) or Babcock and Wilcox (B\&W) and should not be associated with General Electric boiling water reactors. The W-DB-50 reactor trip switchgear is used in a total of 30

85 WM 246-4 A paper recommended and approved by the IEEE Nuclear Power Engineering Committee of the Power Engineering Society for presentation at the IEEE/PES 1985 Winter Meeting, New York, New York, February $3-8,1985$. Manuscript submitted October 10, 1984; made available for printing January 4, 1985.

operating and near-term operating units as listed in Table I. Some 25 operating or near-term operating units use the W-DS-416 reactor trip switchgear. Those units are listed in Table II. There are 8 B\&W operating units and $12 \mathrm{CE}$ operating or near-term operating units that employ the GE-AK-2 type switchgear as listed in Table III. Although the basic GE-AK-2 type switchgear is used by both $B \& W$ and $C E$, there are sufficient dissimilaries between them to refer to the switchgear as the B\&W GE-AK-2 and the CE GE-AK-2 types of switchgear. Two units, Ft. Calhoun and Palisades, do not use any of the three circuit breakers employed in the reactor trip circuits of other pressurized water reactors. Ft. Calhoun and Palisades use contactors for automatic tripping and other types of circuit breakers for manual tripping.

Table I

Units With Westinghouse Reactor Trip Switchgear Type DB-50

\begin{tabular}{|c|c|}
\hline $\begin{array}{l}\text { Beaver Valley } 1 \\
\text { Cook } 1 \\
\text { Cook } 2 \\
\text { Diablo Canyon } 1 \\
\text { Diablo Canyon } 2 \\
\text { Ginna } \\
\text { Haddam Neck } \\
\text { Indian Point } 2 \\
\text { Indian Point } 3 \\
\text { Kewaunee } \\
\text { North Anna 1 } \\
\text { North Anna 2 } \\
\text { Point Beach 1 } \\
\text { Point Beach } 2 \\
\text { Prairie Island } 1\end{array}$ & $\begin{array}{l}\text { Prairie Island } \\
\text { Robinson } 2 \\
\text { Salem } 1 \\
\text { Salem } 2 \\
\text { * San Onofre } 1 \\
\text { Sequoyah } 1 \\
\text { Sequoyah } 2 \\
\text { Surry } 1 \\
\text { Surry } 2 \\
\text { Trojan } \\
\text { Turkey Point } 3 \\
\text { Turkey Point } 4 \\
\text { *Yankee Rowe } 1 \\
\text { Zion } 1 \\
\text { Zion } 2\end{array}$ \\
\hline
\end{tabular}

*DB-25 Breaker with DB-50 UVTA

Table II

Units With Westinghouse Reactor Trip Switchgear Type DS-416

Beaver Valley 2

Braidwood 1

Braidwood 2

Byron 1

Byron 2

Callaway 1

Catawba 1

Catawba 2

Comanche Peak 1

Comanche Peak 2

J. M. Farley 1

J. M. Farley 2
Shearon Harris 1

McGuire 1

McGuire 2

Millstone 3

Seabrook 1

South Texas 1

South Texas 2

V. C. Summer 1

Vogtle 1

Vogtle 2

Watts Bar 1

Watts Bar 2

Wolf Creek 1 
Table III

Units With General Electric

Reactor Trip Switchgear

Type AK-2

\begin{tabular}{|c|c|}
\hline 3abcock and Wilcox & Combustion Engineering \\
\hline $\begin{array}{l}\text { Arkansas } 1 \\
\text { Crystal River } 3 \\
\text { Davis-Besse } 1 \\
\text { Oconee } 1 \\
\text { Oconee } 2 \\
\text { Oconee } 3 \\
\text { Rancho Seco } \\
\text { Three Mile Island }\end{array}$ & $\begin{array}{l}\text { Arkansas } 2 \\
\text { Calvert Cliffs } 1 \\
\text { Calvert Cliffs } 2 \\
\text { Maine Yankee } \\
\text { Millstone } 2 \\
\text { Palo Verde } 1 \\
\text { Palo Verde } 2 \\
\text { Palo Verde } 3 \\
\text { San Onofre } 2 \\
\text { San Onofre } 3 \\
\text { St. Lucie } 1 \\
\text { St. Lucie } 2\end{array}$ \\
\hline
\end{tabular}

An early objective for the Nuclear Regulatory Commission was to determine whether the anomalies associated with the loss of voltage function for each type of switchgear had a common cause or had distinct and separate causes. A chronology of events for each type of reactor trip switchgear and the corresponding corrective actions form the basis for the conclusions reached.

\section{UNDERVOLTAGE TRIP ATTACHMENT EXPERIENCE}

\section{Westinghouse DB-50 Switchgear}

On February 22 and 25, 1983, the reactor trip breakers on Unit 1 of the Salem Nuclear Generating Station failed to open automatically following receipt of signals from the reactor protection system. The manual trip system was used to shut down the reactor. It was determined that the failures to automatically trip were caused by malfunctioning of the undervoltage trip attachments in the reactor trip breakers. These events are thoroughly documented in [1] and [2].

As a result of the Salem anticipated transient without scram, a survey of failures of undervoltage trip attachments on W-DB-50 switchgear in nuclear service as reported in Licensee Event Reports (LER) was conducted. The 17 causes of failure occuring before the Salem event were broken latch pin, burr on trip leaver, excessive latch spring pressure, excessive friction, dirty breaker, sticking . . . not enough force, unknown, not enough force, sticking undervoltage attachment shaft, plunger out of adjustment, binding . . not enough force, missing bushing, failed metal latch, loss of spring tension, undervoltage coil binding, under voltage coil sticking and binding of relay mechanisms. These failures occurred during the time period May 1971 through January 1983. The failure to trip which caused the Salem event was attributed to a number of scenarios, all of them documented in [3], [4], [5] and [6]. The common elements in these failure scenarios are friction and binding.

After determining the cause of failure to trip on loss of voltage, corrective actions were taken. These corrective actions were performing maintenance, replacing nonconforming or broken parts and initiating a design review for possible hardware changes. Prior to the Salem event the frequency, procedures and basis for lubricating the undervoltage trip attachment had not been established rigorously. For the failures identified above, the most frequent corrective action taken was the application of lubricant to the undervoltage trip attachment. In some instances the cause of failure was that the specification (dimensions, finish) for the undervoltage trip attachment was not met for parts identified as critical to the device. The remedial action was to inspect during the manufacturing process all the parts identified as critical, that is, a $100 \%$ inspection. Also one of the design reviews resulted in a design change in the early seventies.

\section{Westinghouse DS-416 Switchgear}

On February 4, 1983, at McGuire Unit 2, reactor trip breaker " $B$ " failed five consecutive times to trip on loss of power during routine reactor protection systems functional testing. After the breaker was operated by the shunt trip, all subsequent loss of voltage trip tests that day were successful. On February 16, 1983, at McGuire Unit 2 reactor trip breaker "B" failed several times during routine reactor protection system response time testing. On March 18, 1983, at McGuire Unit 2 reactor trip breaker "B" failed three out of ten attempts during retesting in the switchgear cubicle; that testing was initiated because of the February 1983 experience with this breaker. The breaker was moved to a maintenance area for additional testing. In over 100 tests, one or two additional failures occurred. During this testing, after each test of the undervoltage device that was not successful, the breaker was cycled manually by operating the local mechanical trip. The diagnosis was binding of the undervoltage trip device due to insufficient dimensional clearance between two of its moving parts (the moving core and the roller bracket). Westinghouse determined that certain clearances on the undervoltage device were critical with respect to dimensions and tolerances. On March 31, 1983 at McGuire Unit 2, all four reactor trip breakers failed to pass the special dimensional checks specified by Westinghouse. On March 28, 1983, at McGuire Unit 2, the bearing surface at the ends of the trip shafts of the main assemblies were found to have been ground down rather than machined, leaving a finish considered too rough for a bearing surface. On April 2, 1983, McGuire Unit 2 reactor trip breaker " $B$ " failed to function upon the first operation of the breaker after installation. This failure occurred during a functional check in preparation for control rod drop tests. The diagnosis was dislocation of the roller arm shaft of the undervoltage device due to a missing retaining clip ring from the end of the shaft.

On March 19, 1983, at McGuire Unit 1 reactor trip breaker "A" failed twice during routine reactor protection systems response time testing. The diagnosis was insufficient dimensional clearance between the undervoltage trip device and the trip shaft of the main breaker assembly. On March 31, 1983, at McGuire Unit 1, all four reactor trip breakers failed to pass the dimensiorial checks specified by Westinghouse. Subsequently that day, a functional test of reactor trip breaker " $B$ " was conducted and it failed to trip. On April 11, 1983, at McGuire, one of six new modified undervoltage trip devices failed to pass the dimensional checks.

In an attempt to acquire acceptable undervoltage trip devices for the McGuire units, the devices at the Catawba station were checked. On March 31,1983 , six of the eight Catawba reactor trip breakers failed to pass the dimensional 
checks. On April 1, 1983, the remaining two Catawba reactor trip breakers were transferred to the McGuire station, inspected, serviced, cycled ten times on the bench, and installed in the Unit 2 reactor trip breaker " $A$ " and " $B$ " cubicles. During the inspection, it was verified that all clip rings were in place.

On April 6, 1983, at the V.C. Summer plant, one reactor trip breaker undervoltage device failed to pass the special dimensional checks and one retaining clip ring was missing.

On April 12, 1983, four reactor trip breaker undervoltage devices for the Vogtle nuclear station had unacceptable dimensional checks. On April 13, 1983, at Farley Unit 1, three of the four reactor trip breaker undervoltage devices failed to pass the dimensional checks. On April 15, 1983, at Farley Unit 2, one undervoltage device failed to perform in the "B" bypass reactor trip breaker. The failure was attributed to the gap between the undervoltage device and the trip shaft of the main breaker assembly being too large. All four undervoltage devices were replaced by new modified undervoltage devices. Table IV is a set of selected occurrences.

The remedial actions taken for the above identified failures were performing maintenance and initiating a design review for possible hardware changes. For this undervoltage trip attachment lubrication is performed only during the manufacturing process and is not part of maintenance. The dimensional checks of clearances with respect to the undervoltage device are an important part of the recommended maintenance and are now included in the inspections before shipment by the manufacturer to the utility. The design review revealed a change to the groove for the retaining clip ring was required. Additional information is contained in [7] and [8].

Table IV

Experience With Westinghouse DS-416 Reactor Trip Switchgear

\begin{tabular}{|c|c|c|}
\hline \multirow[b]{3}{*}{ Facility } & \multicolumn{2}{|c|}{ Occurrences } \\
\hline & No & Failed to Pass \\
\hline & Trip & Dimensional Checks \\
\hline
\end{tabular}

McGuire 2

1

3

1

1

McGuire 1

2

14

Catawba

6

Summer

Farley 1

3

Farley 2

1

Vogtle
General Electric AK-2 Type Switchgear

On March 1 and 8, 1983 at San Onofre Nuclear Generating Station (SONGS), as a result of the failure of reactor trip circuit breakers to function at Salem, an 18 month surveillance test was performed independently testing undervoltage and shunt trip functions of the reactor trip switchgear. Four of the total of 18 reactor trip breakers tested failed to trip following actuation of their undervoltage devices. All 18 tripped following actuation of the shunt trip device. On October 2, 1983 response time measurements for the reactor trip switchgear at SONGS Unit 2 showed one reactor trip breaker was slow, that is, the response time via the undervoltage trip attachment of the breaker exceeded the acceptance criterion, and a second breaker had failed, that is, the breaker did not open at all. The breaker which failed to trip on loss of voltage had previously failed in March 1983.

As a consequence of the switchgear anomalies experienced at SONGS Units 2 and 3 in March 1983, a program of preventative maintenance (servicing) to be performed quarterly and a program of surveillance testing to be performed monthly was instituted. The anomalies of 0ctober 2, 1983 occurred at the time of the second maintenance servicing. As a result the schedule for servicing was accelerated to every 60 days (from every 90 days) and surveillance testing continued on a monthly basis.

At SONGS Units 2 and 3 on 0ctober 28, 1983, while routine monthly surveillance testing was being performed on the reactor protection system, the armatures of the undervoltage trip attachment for two reactor trip breakers were observed to be in a midposition rather than fully down in contact with the air gap adjusting screw. The switchgear was reset, observed to operate properly, and the armatures of the undervoltage trip attachment were observed to be properly positioned at that time. On October 31, 1983, the armatures of the undervoltage trip attachment of the reactor trip breakers were visually inspected. This inspection revealed that the undervoltage armatures of one reactor trip breaker on Unit 2 and two reactor trip breakers on Unit 3 were not properly positioned. The Unit 3 switchgear had been tripped and reset between 0ctober 28 and 0ctober 31, 1983 without verifying the armature position. These three reactor trip breakers were reset, observed to operate properly and the armatures of the undervoltage trip attachment positioned properly. On December 4, 1983, monthly surveillance testing determined that two reactor trip breakers did not meet the response time acceptance criterion. See [9] for additional information.

Maine Yankee conducted response time tests of its reactor trip switchgear on November 17, 1983. A11 8 reactor trip breakers experienced slow response times. One of the breakers had not opened at the 7 minute point when the test was terminated; the others had response times ranging from $229 \mathrm{~ms}$ to $10 \mathrm{~s}$. When this event was investigated it was revealed that during the previous test in August 1983 when the reactor trip breakers were tested, al1 8 reactor trip breakers failed to meet a $100 \mathrm{~ms}$ response time acceptance criterion. The response times in August ranged from $221 \mathrm{~ms}$ to $7 \mathrm{~s}$. Performing maintenance on the reactor trip switchgear had an immediate effect in that the response time met the acceptance criterion of $100 \mathrm{~ms}$. However, in some instances, within days the switchgear 
response time exceeded the $100 \mathrm{~ms}$. Prior to March 1983 , loss of voltage response time testing was not conducted at Maine Yankee, only functional testing was performed. Functional testing involves actuating the shunt trip simultaneously with the loss of voltage trip. There were two instances between March and December 1983 of a reactor trip breaker failing to open via the undervoltage trip. In one of these a post-trip demand inspection revealed that the armature of an undervoltage trip attachment was in the midposition.

On November 30, 1983, Arkansas Nuclear Operations (ANO), Unit 2 tested all 8 reactor trip breakers and found one breaker with response times between 150-180 ms (in three tests). All other switchgear had response times less than $50 \mathrm{~ms}$.

Two reactor trip breakers failed at Oconee Unit 1 on December 19, 1983. During on-line functional testing, one A.C. reactor trip breaker appeared to trip in $8 \mathrm{~s}$ on the first attempt and in $5 \mathrm{~s}$ on the second attempt. Subsequent functional testing revealed that one of the D.C. reactor trip breakers seemed to trip in about $3 \mathrm{~s}$. Previously during the on-line functional tests in November 1983, one reactor trip breaker had responded in an obviously slow manner. Maintenance was performed, including revitalization of the lubricant in the latch roller bearing and the trip shaft bearings, and this remedied the slow response times.

During on-line monthly reactor trip breaker response time testing via the undervoltage trip attachment at Calvert $\mathrm{Cliffs}$, two of the 8 reactor trip breakers failed with response times in excess of $1 \mathrm{~s}$. A revised preventative maintenance program had been instituted in July 1983. These were the first failures since then. One reactor trip breaker was found to have insufficient positive trip travel. The other reactor trip breaker had a low pickup voltage for the undervoltage attachment and a non-repeatable latch engagement.

Selected GE-AK-2 type reactor trip breaker anomalies that have occurred through December 1983 are presented in summary form in Table $V$.

In the GE-AK-2 type of switchgear the undervoltage device per se requires no lubrication. A mechanical latch keeps the switchgear armed once the switchgear has been closed. The mechanical latch mechanism includes a roller bearing. Two bearings support the trip shaft. Switchgear operability depends on the interaction between the undervoltage device and the latch mechanism remaining unchanged over time. For example, given that the undervoltage device produces a constant output force, the switchgear would not open if the force required to collapse the latch mechanism increased beyond some threshold value. This could occur due to degraded lubricant in the latch roller bearing or some other age related phenomenon.

The major contributing factors to the anomalies experienced in switchgear operation on loss of voltage as just described were insufficient or degraded lubricant in the trip shaft and latch roller bearings, undervoltage device armature pickup voltage being below the recommended voltage and clearances not within that specified by the manufacturer. Remedial actions were to perform maintainence, in this case to revitalize the lubricant as oppose to appyling lubricant, adjust the pickup voltage, adjust the clearances and to initiate design reviews.

Table $V$

Experience with General Electric AK-2 Type Reactor Trip Switchgear

\begin{tabular}{lccc} 
& \multicolumn{3}{c}{ Occurrences } \\
\cline { 2 - 4 } STlow & No & Armature in \\
SONGS 2 & Trip & Trip & Midposition \\
\cline { 2 - 4 } & & 3 & \\
& 1 & 1 & 1 \\
& 2 & &
\end{tabular}

SONGS 3

1

$\begin{array}{llll}\text { Maine Yankee } & 8 & & \\ 7 & & \\ 2 & & \\ 3 & & 1 \\ 1 & & \\ 1 & & \\ 1 & & \end{array}$

ANO 2

$\begin{array}{ll}\text { Oconee } & 1\end{array}$

Calvert Cliffs 2

\section{DISCUSSION}

The experience with the undervoltage trip attachments on the various types of switchgear in the reactor protection systems is difficult to organize and place in categories. Focusing on the corrective actions taken as opposed to the causes of failure, which in some cases were never really conclusively determined and in other cases involved differing professional opinions, some conclusions can be drawn. Generally the corrective action involved making adjustments to bring the undervoltage device and the switchgear into compliance with vendor specifications or the application of a lubricant (including the revitalizing of the lubricant). Adjustments were necessary due to either improper settings at the vendor, improper settings from previous maintenance or time in service that caused acceptable initial settings to become unacceptable. Lubrication appeared to be a remedy for any type of anomaly whose cause was not immediately obvious, particularly with regard to the undervoltage trip attachment of the W-DB-50. Slow trip times, which seem to be indigenous only to the GE-AK-2 type switchgear, were remedied by the revitalization of the lubricant in the latch roller bearing in the switchgear. On more than one occasion the remedy was only temporary in that slow trip times were observed in some instances within days of the revitalization of the lubricant. Generally, sticky or slow operation via the loss of voltage function resulted in lubrication as a remedy.

The users of switchgear are relying on maintenance to achieve acceptable performance and to remedy many of the anomalies experienced. The content of that maintenance and the frequency of application were early issues between the users 
and the Commission. Surveillance with parameter trending, such as the force required to trip the switchgear, force produced by the undervoltage device or the trip response time is to be used to establish possible precursors to switchgear failure and to establish the maintenance interval. The lifetimes of the undervoltage devices should be established. The lifetime of the lubricants presently being used needs to be determined conclusively and verified by time in service. Although the switchgear and the undervoltage trip attachment underwent development testing by the manufacturers, the test objectives were not to rigorously establish a device lifetime, the content of maintenance, the frequency of maintenance and lubricant lifetime.

\section{CONCLUSION}

The causes of the anomalies in each type of switchgear with regard to the undervoltage trip function were generally separate and distinct due mainly to differences in design. But the basic common causes were the absence of maintenance (content and frequency) and the absence of a definitively established lifetime for the undervoltage trip attachment or its ability to initiate a trip on loss of voltage. Rigorous switchgear testing would have eliminated many of the anomalies experienced. Performance degradation caused by mechanical, age-related phenomena can be revealed by a properly conducted comprehensive testing program. In the experience described above, its not the switchgear, but the undervoltage trip attachment and the relationship between the undervoltage trip attachment and the switchgear that has not been sufficiently examined. The content of maintenance, the frequency of maintenance and the lifetime of the undervoltage trip attachment should have been known definitively before this safety related equipment was placed in service. Instead maintenance and surveillance of the switchgear while it is in service is being used to determine the maintenance interval, the content of maintenance and the lifetime of the undervoltage trip attachment. Trending of various switchgear parameters is being used to establish a means of predicting either degradation in performance or failure to trip of the switchgear on loss of voltage. These efforts, though belated, should reduce the number of failures experienced by undervoltage trip attachments on reactor trip switchgear. In addition a separate rigorous test program ought to be conducted to verify the data being collected at the facility level.

\section{REFERENCES}

[1] USNRC, Generic Implications of ATWS Events at the Salem Nuclear Power Plant, NUREG-1000, Volume 1, April, 1983.

[2] USNRC, NRC Fact-Finding Task Force Report on the ATWS Events at Salem Nuclear Generating Station, Unit 1 on February 22 and 25, 1983, NUREG-0977, March, 1983.

[3] USNRC, Safety Evaluation Report related to plant restart of Salem Nuclear Generating Station, Unit Numbers 1 and 2, NUREG-0995, December, 1983.

[4] G. Toman, Evaluation of Failure to Trip of Reactor Trip Circuit Breakers on February 22 and 25, 1983 Salem Nuclear Generating Station Unit 1, Franklin Research Center Technical Evaluation Report, May 9, 1983.
[5] G. Toman, Evaluation of Failure to Trip of Reactor Trip Circuit Breakers on February 22 and 25, 1983 Salem Nuclear Generating Station Unit 1, Franklin Research Center Technical Evaluation Report, April 7, 1983.

[6] R. Cranisky and G. Toman, Evaluation of a New and Used Westinghouse DB-50 Undervoltage Trip Attachment Salem Nuclear Generating Station Unit 1, Franklin Research Center Technical Evaluation Report, October 27, 1983.

[7] U.S. NRC, Safety Evaluation Report related to operation of McGuire Nuclear Station Units 1 and 2, NUREG-0422, Supplement No. 7, May 1983.

[8] G. Toman and J. Stone, Evaluation of McGuire Units 1 and 2 Undervoltage Trip Attachment Failures, Franklin Research Center Technical Evaluation Report, July 13, 1983.

[9] G. Toman, D. Schmity and R. Cranisky, Evaluation of Failure to Trip of Reactor Trip Circuit Breakers San Onofre Nuclear Generating Station Units 2 and 3, Franklin Research Center Technical Evaluation Report, July 13, 1983.

Robert J. Wright was born in Youngstown, $\mathrm{OH}$, on January 30, 1941. He received the B.S. degree in Mechanical Engineering from Carnegie-Mellon University, Pittsburgh, the M.S. degree in Engineering Science from New Jersey Institute of Technology, Newark and the Ph. D. degree in Mechanical Engineering from Rutgers University, New Brunswick, in 1963, 1965 and 1970, respectively. He also received the M.B.A. degree from Duquesne University, Pittsburgh, PA in 1977.

In 1981 he joined the U.S. Nuclear Regulatory Commission, Washington, D.C. His work has been in the equipment qualification area. He is currently Senior Equipment Qualification Engineer in the Office of Nuclear Reactor Regulation.

Dr. Wright is a member of Sigma $X_{i}$ and Betta Gamma Sigma. He is a Registered Professional Engineer in the states of Pennsylvania and Maryland.

Vincent S. Noonan received his B.S. degree in Aeronautical Engineering from the Parks College of Aeronautical Technology, St. Louis University, in 1959. He received his M.S. decree in Engineering Mechanics from the University of Missouri in 1972.

In 1959 he joined the McDonald Douglas Aeronautical Space Corporation and worked in the field of structural dynamics. In 1974 he joined the United States Nuclear Regulatory Commission. He is currently Chief of the Equipment Qualification Branch. He is a member of the American Society of Mechanical Engineers committee on equipment qualification. 